\title{
Impact of urban sprawl to cultural heritage monuments: The case study of Paphos area in Cyprus
}

\author{
Athos Agapiou a,*, Dimitrios D. Alexakis a , Vasiliki Lysandrou b, Apostolos Sarris c

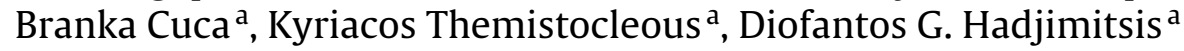

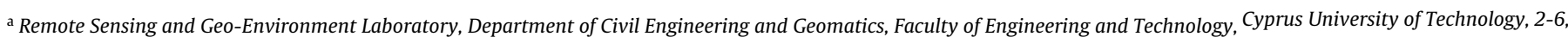 \\ Saripolou str., 3603 Limassol, Cyprus \\ ${ }^{\mathrm{b}}$ Restoration of Monuments and Sites, Kykkos Museum, Nicosia, Cyprus \\ ${ }^{\mathrm{c}}$ Laboratory of Geophysical-Satellite Remote Sensing and Archaeo-environment, Institute for Mediterranean Studies, \\ Foundation for Research and Technology, Hellas (FORTH), Crete, Greece
}

\section{ABSTRACT}

Urbanisation processes as a result of population growth, migration and infrastructure initiatives have a direct impact to cultural heritage sites. This paper aims to monitor growth dynamics of the urbanisation process that took place in the Paphos district, southwest Cyprus during the last decades, and evaluate its impact to monuments and archaeological sites. In this extensive area, several important archaeological sites and monuments are found, while some of them are also listed in the UNESCO catalogue of World Cultural Heritage sites. GIS and remote sensing techniques have been used in order to map the listed monuments in the Paphos District, as well as to record spatial and temporal land use changes since the 1980s. The spatial patterns of urban sprawl are studied and analysed using archive time series medium resolution Landsat ETM+ and TM satellite imagery. In addition, a DMSP-OLS night-ime image was also used. Several supervised and unsupervised classification algorithms have been evaluated and examined for this purpose. Additionally, Markov equation were applied in an attempt to predict future urban expansion The final outcomes revealed that a dramatic increase of the urban areas took place in the last years in Paphos district, and as a result significant pressure is expected on archaeological sites found in the peri-urban areas.

\section{Introduction}

Urbanization process has been linked to a variety of resource and environmental problems worldwide, such as habitat loss, species extinction, land cover change, and alteration of hydrological systems [1]. Unprecedented urbanization, characterized by demographic shift from rural to urbanized areas and urban land expansion, has taken place globally in the last several decades. As it is estimated the world urban population has been increased from 1.35 billion in 1970 to 3.63 billion in 2011 [2]. Global urban

\footnotetext{
* Corresponding author. Remote Sensing and Geo-Environment Laboratory, Department of Civil Engineering and Geomatics, Faculty of Engineering and Technology, Cyprus University of Technology, 2-6, Saripolou str., 3603, Limassol, Cyprus. Tel.: +35 725002471

E-mail addresses: athos.agapiou@cut.ac.cy (A. Agapiou), dimitrios.alexakis@cut.ac.cy (D.D. Alexakis), vaslysandrou@yahoo.it (V. Lysandrou), asaris@ret.forthnet.gr (A. Sarris),d.hadjimitsis@cut.ac.cy (D.G. Hadjimitsis).
}

area, which has quadrupled during 1970-2000, is reported to grow on average twice as fast as urban population in recent years and expected to triple the global urban area in circa 2000 by 2030 [3].

Urbanization is proceeding on an unprecedented scale while the rapid and frequently uncontrolled development is transforming urban areas and their surroundings. This transformation may cause fragmentation and deterioration to heritage throughout the world. Indeed, over the last few decades, modern urbanization, including investments in modern infrastructure in central regions, has led to intensive changes in land use [4]. A large part of this urban population lives in peri-urban regions while in developing countries the issue of peri-urbanization is growing in importance due to continuous and rapid urbanization in these countries [5]. Increase in population is connected to urban and infrastructural expansion. Urban sprawl is associated not only with changes in land cover, but also to ecological, climate and social transformations [6]. City boundaries continue to expand, consuming more and more of rural areas, forests, heritage places and other important non-urban areas. 
Therefore, urbanization processes as a result of population growth, migration and infrastructure initiatives have either a direct or indirect impact on the character of the cultural heritage sites.

As Al-Houdalieh and Sauders [7] argue, aspects of human development deemed positive and progressive construction, cultivation and expansion equally threaten the longevity and security of cultural heritage, yet often fail to generate the same widespread condemnation. The formidable forces of unplanned development, incessant productivity, rampant innovation, and heedless technical advance can dramatically change the environment and landscape of an area. Several researchers agree that urban expansion is likely to pose one of the most significant threats to the archaeological resources and therefore appropriate measures are needed to miti-gate against their destruction without the adequate documentation or investigation $[8,9]$.

Cultural heritage management, comprising both archaeological sites and archaeo-landscapes, is included by many recent European policies, laws and national reports on the state of the environment [10]. In order to support the protection of natural and cultural heritage, emphasis is given to the integration of strategies into local development processes and urban planning regarding cultural heritage management and planning. Therefore, up-to-date maps and related information are very important for urban planners in order to design development plans sensitive to cultural heritage sites. Geographic information system (GIS) integrated with Remote sensing are considered to be of the most efficient tools for analyzing, mapping and retrieving RELIABLE information.

Remote sensing and GIS have been widely used for heritage management [11-13]. Special attention is given by some researchers to map existing urban growth and risk assessment in the vicinity of Cultural Heritage sites [14], while other studies attempt to monitor anthropogenic and natural threats to archaeological sites [9]. The integration of these data sets with other multi-sources information, such as historic maps, can be also considered to provide public authorities with geo-portals and innovative tools for more informed decision-making [15].

Despite the integrated use of remote sensing and GIS within archaeological research and management, an effort was made in order to apply prediction hazard models for monitoring threats in existing archaeological sites. Such prediction models may be used to map future urban areas, and therefore, to support local authorities to evaluate any potential threats for these sites. This paper seeks to highlight some of the key tools provided by remote sensing and GIS, through an extensive case study and at the same time to demonstrate how these may be employed for a more efficient cultural heritage management and urban planning.

The paper uses time series multispectral satellite images and predictive models to understand future urban settlement patterning, with special focus to areas in the vicinity of archaeological sites. Indeed, multispectral freely distributed satellite images from 1984 until 2010 have been exploited. Since these images are georeferenced, the final outcomes (i.e. urban areas for each period examined in this study) were directly overlaid and compared. In order to examine the diachronic evolution of urban sprawl in the vicinity of these sites and monuments, other cultural heritage infor-mation (i.e. archaeological sites and monuments) was used The spatial analysis was carried out in a GIS environment.

\section{Case study area}

Paphos district located in the south-western Cyprus was selected as a case study since it combines both World Heritage Monuments and isolated monuments in other inaccessible sites (Fig. 1). Moreover, monuments and sites in Paphos can be found both in urban and rural areas, low altitude (nearly sea level) and high level (highest mountain-picks of the island), near and far from the coastlines, forest areas, industrial zones etc. This multidimensional reality of Paphos' antiquities can be used to extract useful and comparative results with respect to urban sprawl and its effects on the monuments of cultural interest, within the same province. Furthermore, Paphos is known for the construction boom that took place in the 1980s through massive excavations giving place to modern luxurious hotels and villas. Nowadays construction is still ongoing however in a smaller scale due to economic crisis.

Several important monuments and cultural heritage sites are found in the area of Paphos. Among them are the Nea Paphos and the Tombs of the Kings archaeological sites, listed by UNESCO as World Heritage Monuments.

Nea Paphos is situated on a small promontory on the southwest coast of the island. According to written sources, the town was founded at the end of the 4th century by Nicocles, the last king of Palaipaphos. After the Arab raids during the 7th century, Nea Paphos went through a period of decline, which lasted a few centuries, and was thus reduced in size. The town regained some of its importance during the Byzantine and the medieval periods but from the Venetian period onwards the coastal settlement of Nea Paphos was abandoned and the population began to move further inland where the present town of Paphos developed. The Tombs of the Kings is the impressive necropolis that is located just outside the walls, to the north of Paphos town. It was built during the Hellenistic period (3rd century B.C.) to satisfy the needs of the newly founded Nea Paphos.

The historical town centre of Paphos can be characterized of equal importance, as it is the area that keeps the historical and cultural continuity of the town from the ancient times till today. Some of the historical buildings of this area are the first Manor houses of Ktima (dated in the early 20th century), Paphos Holy Bishopric (1910 building), Agios Theodoros Metropolitan Church (built in 1896), Ethnographical Museum (build between the late 19th and early 20th century), Town Hall (built in 1955), the Municipal Library (built during the 1940s), etc.

\section{Methodology and resources}

Multi-temporal Landsat satellite images have been used for monitoring urban expansion over the area of Paphos, during the period 1984-2010. The overall methodology is composed by five steps. Firstly, classification analysis was applied so as to map the urban sprawl over time (Step 1). Additionally, further image analysis of the Landsat data as well night-time data has been performed, in an attempt to verify the final results of classification analysis (Step 2). All monuments of the Paphos district were georefenced in a common geodetic system (Step 3). Furthermore, GIS spatial analysis (Step 41) was carried out to monitor and map urban expansion in the last decades in the vicinity of the archaeological sites. Finally, a projection map of 2020 was processed (Step 5) to identify any future urban pressure to cultural heritage sites.

In detail, 4 multispectral Landsat 5 TM and Landsat 7 ETM+ were used (path/row: 176/36). A satellite image - with no or limited cloud cover - for each decade was used (1980-2010). The Landsat space program allows us to go back almost 30 years (1984). Landsat images have a spatial coverage of $170 \times 183 \mathrm{~km}$, while their spatial resolution is $30 \mathrm{~m}$. Such kind of data has been successfully used for classification purposes in a variety of disciplines [16-18]. Further characteristics of the Landsat data are shown in Table 1.

\subsection{Step 1: classification of satellite images}

Several classification techniques have been evaluated for the purpose of this study. As Blaschke [19] argues, classifiers are faced with such difficulties as information weighting and 


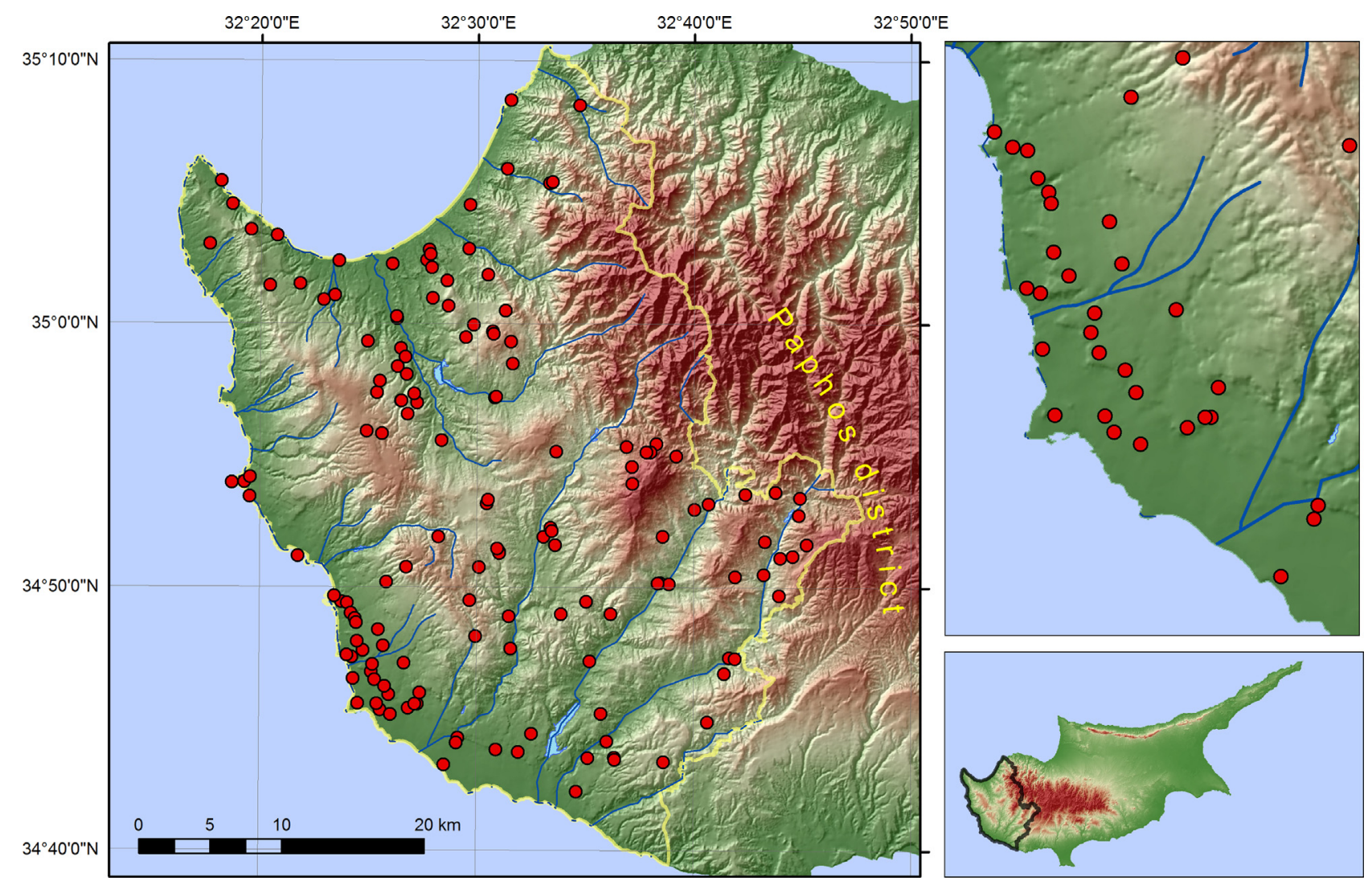

Fig. 1. Monuments and archaeological sites of Paphos district

decision-making when applied to land cover classification and thus making the classification accuracy hard to meet the requirements of users. In the literature different supervised or unsupervised classification techniques exist, e.g. per-pixel based maximum likelihood, nearest neighbour, fuzzy classifications, object-oriented multi-resolution segmentation, artificial neural networks, decision tree-based classification, and rule-based classification [19-22]. Using areas of interest, the overall performance of each technique can be measured and evaluated based on statistical analysis.

In an attempt to maximize the correctness of the classification results, both simple and more complex algorithms have been used. Indeed, minimum distance to means (MD) [20] and maximum likelihood classifiers (ML) [20] were examined. In addition, Spectral Angle Mapper (SAM) $[20,21]$ and Support Vector Machine (SVM)[22] were also tested. Other classifiers, such as object-oriented [20,21], fuzzy logic $[20,21]$ or texture analysis [21] were not evaluated, since high classification accuracy was achieved from the previous mentioned algorithms.

The MD algorithm is a statistical technique that classifies the image based on the closest distance of training areas using the spectral characteristics of the pixels [20]. Usually it is possible to specify a maximum distance threshold. If the distance is still further away than that threshold, it is assumed that none of the groups is similar enough and the result will be "unknown". ML algorithm performs

Table 1

Satellite data used for monitoring urban growth.

\begin{tabular}{llll}
\hline No & Satellite & Sensor & Date of acquisition \\
\hline 1 & Landsat 5 & TM & 22 October 1984 \\
2 & Landsat 5 & TM & 04 August 1990 \\
3 & Landsat 7 & ETM+ & 24 September 2000 \\
4 & Landsat 5 & TM & 27 August 2010 \\
\hline
\end{tabular}

classification based on the normal probability density function [21]. The SAM algorithm is an automated method, which calculates and classifies the spectral angle between the pixels of the image [21]. This method is insensitive to illumination since the SAM algorithm uses only the spectral direction and not the spectral distance. SVM is a machine-learning technique that is well adapted to solving non-linear, high dimensional space classifications. As Heumann [23] argues, SVM can be used for remote sensing applications, for classi-fication of either multispectral or hyperspectral data, in which there is a spectral similarity between the pixels. SVM aims to identify the boundaries between classes in n-dimensional spectral-space [24]. As Paneque-Gálvez et al. [25] argue, SVM classifiers have been shown to attain high accuracies in land use cover mapping and outperform other algorithms.

\subsection{Step 2: principal component analysis and DMSP-OLS analysis}

Supplementary to classification analysis, further exploitation of the data was carried out in order to verify the final outcomes. Princi-pal component analysis (PCA) was applied to detect any significant changes under the period examined (1984-2010). PCA is a statisti-cal analysis process of the image that accounts the variation of the pixel values within the image [21]. In addition, a radiance calibrated Defence Meteorological Satellite Program Operational Line Scanner (DMSP-OLS) night-time data set for 2010 was used. A direct com-parison of this dataset with urban areas of 2010, as classified from the Landsat sensor, was applied to evaluate the potential use of nigh-time images. This image was prepared from individual fixed gain images captured by satellites F18 [26].

The DMSP-OLS has been imaging night-lights since the early 1970s, while the more recent digital data have been used to produce annual global composites of temporally stable night-time lights from 1992 to 2008 [26]. The result is a set of composite images 
Table 2

Ground truth (percentage) from the image taken in 2010 using the SVM algorithm.

\begin{tabular}{lrrrrr}
\hline Class & Urban & Water & Vegetation & Soil-A & \multicolumn{1}{c}{ Soil-B } \\
\hline Urban & 90.50 & 0.00 & 0.00 & 0.00 & 0.00 \\
Water & 0.00 & 100.00 & 0.00 & 0.00 & 0.00 \\
Vegetation & 0.00 & 0.00 & 96.64 & 0.00 & 2.19 \\
Soil-A & 9.50 & 0.00 & 0.00 & 90.75 & 0.73 \\
Soil-B & 0.00 & 0.00 & 3.36 & 9.25 & 97.08 \\
Total & 100.00 & 100.00 & 100.00 & 100.00 & 100.00 \\
\hline
\end{tabular}

in which each 30 arc second ( $\sim 1 \mathrm{~km}$ at the equator) pixel gives the annual average brightness level in units of 6 bit digital numbers (DN). Visible pixels have relative values ranging from 0 to 63 , rather than absolute values in $\mathrm{W} / \mathrm{m}^{2}$.

\subsection{Step 3: geo-referenced on cultural heritage sites}

All monuments listed from the Department of Antiquities of Cyprus were mapped in a common geodetic system (CGRS93, LTM) (Fig. 1). Local cadastral maps of the Paphos district were used to map these monuments and sites. The local cadastral maps are currently used by the Department of Land and Surveys of Cyprus for cartographic purposes and field surveys.

\subsection{Step 4: GIS spatial analysis}

The final results (i.e. classification analysis and monuments) were imported into the GIS environment for further analysis. A buffer zone of $500 \mathrm{~m}$ (i.e. 15 pixels zone) from each monument was created in order to examine the land use changes within this area around the monuments.

\subsection{Step 5: urban pressure projection to 2020}

A simulation of urban areas and urban pressure in the vicinity of archaeological sites and monuments for 2020 was finally applied. The final result was a land use map of the year 2020 indicating the future urban areas. The prediction model was based upon the Stochastic Markov Model [27]. Markov model is used to simulate changes (i.e. 2020) in the future spatial-temporal pattern of land use based transition rules, which were obtained through spatial overlay analysis using GIS on land use types between 2000 and 2010. Some applications of Markov models can be found in $[28,29]$.

\section{Results}

\subsection{Classification analysis}

The Landsat dataset was classified into four main land cover types (built areas; water bodies; vegetation and land). The classification results from the Landsat imagery display a complex urban footprint of a coalescent urban core and a complex, sprawling suburban to splinter development, in rural areas. Urban footprints during the last 30 years were then mapped, based on the classification results.

Fig. 2 illustrates the urban expansion of the Paphos town during the last 30 years, as recorded using remote sensing techniques. Each colour represents a different year of observation (black colour indicates urban areas back in 1984; orange colour refers to the urban areas of 1990; red colour refers to the urban areas of 2000 and green colour indicates the urban areas of 2010). As it is clearly shown, a dramatic expansion took place in Paphos region, especially during the last 20 years (1990-2010). New urban areas were developed in the surroundings of the existing town, while at the same period an extensive urbanization was observed in the northwest area (Peyeia region).

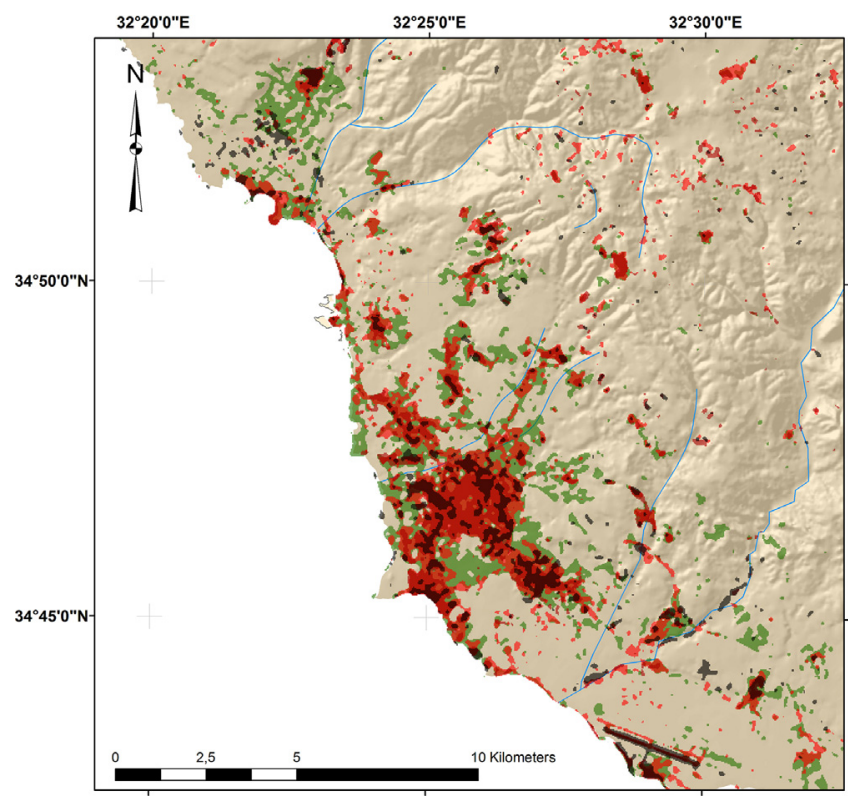

Fig. 2. Urban expansion of the Paphos city from 1984 to 2010. Black colour indicate urban areas back in 1984; orange colour the urban areas of 1990; red colour the urban areas of 2000 and green colour the urban areas of 2010.

Table 3

Overall accuracy and Kappa coefficient for Landsat 2010 from different classifiers.

\begin{tabular}{lllll}
\hline Classifier & NN & ML & SAM & SVM \\
\hline Overall accuracy (\%) & 77 & 89 & 70 & 95 \\
Kappa coefficient & 0.71 & 0.87 & 0.60 & 0.93 \\
\hline
\end{tabular}

In addition, Fig. 2 shows that urban areas (red color) are found in the southwest part of the Paphos district, near the coastline. This is a typical allocation for cities in a close proximity to the sea for the rest part of the island of Cyprus, as well as for Mediterranean countries in general. The classification results indicated the dynamic nature of vegetation since satellite images were taken from different periods. As it was found, the soil coverage was ranged from 770 to $1087 \mathrm{~km}^{2}$ while vegetated coverage was estimated from 240 to $600 \mathrm{~km}^{2}$. This dynamic range may lead to mis-classification result (for vegetation studies) since vegetation growth information is not involved (i.e. different vegetation types may have similar spectral features in a single image, based on their phenological stage). Therefore, both soil and vegetation classes can be either maximized or minimized according to the meteorological conditions of the area. Several studies have shown the potential of using both multi-temporal and multispectral images (Landsat and MODIS images) in order to overcome this limitation [30,31].

For evaluation purposes of the classification results, the $k$ ("KHAT") [32] statistic was calculated. $k$ statistic measures the difference between the actual agreement of reference (i.e. truth) data and the classification results. A true agreement approaches 1 while chance agreement approaches 0 . The classification results based on the SVM classifier were found very accurate since the $k$ value was ranged from 88-96\% (1984: 89\%; 1990: 91\%; 2000: 96\%; 2010: 93\%) while the overall accuracy was estimated from 92-96\% (1984: 93\%; 1990: 91\%; 2000: 96\%; 2010: 95\%) for all Landsat images. Some typical statistics from the ground truth data (percentage) using the image with overpass in 2010 are shown in Table 2. Table 3 , shows the statistics ( $k$ statistic and overall accuracy) from other classifiers for Landsat image of 2010. As it was found, the SVM classifier had better performance from the rest of the classifiers. 

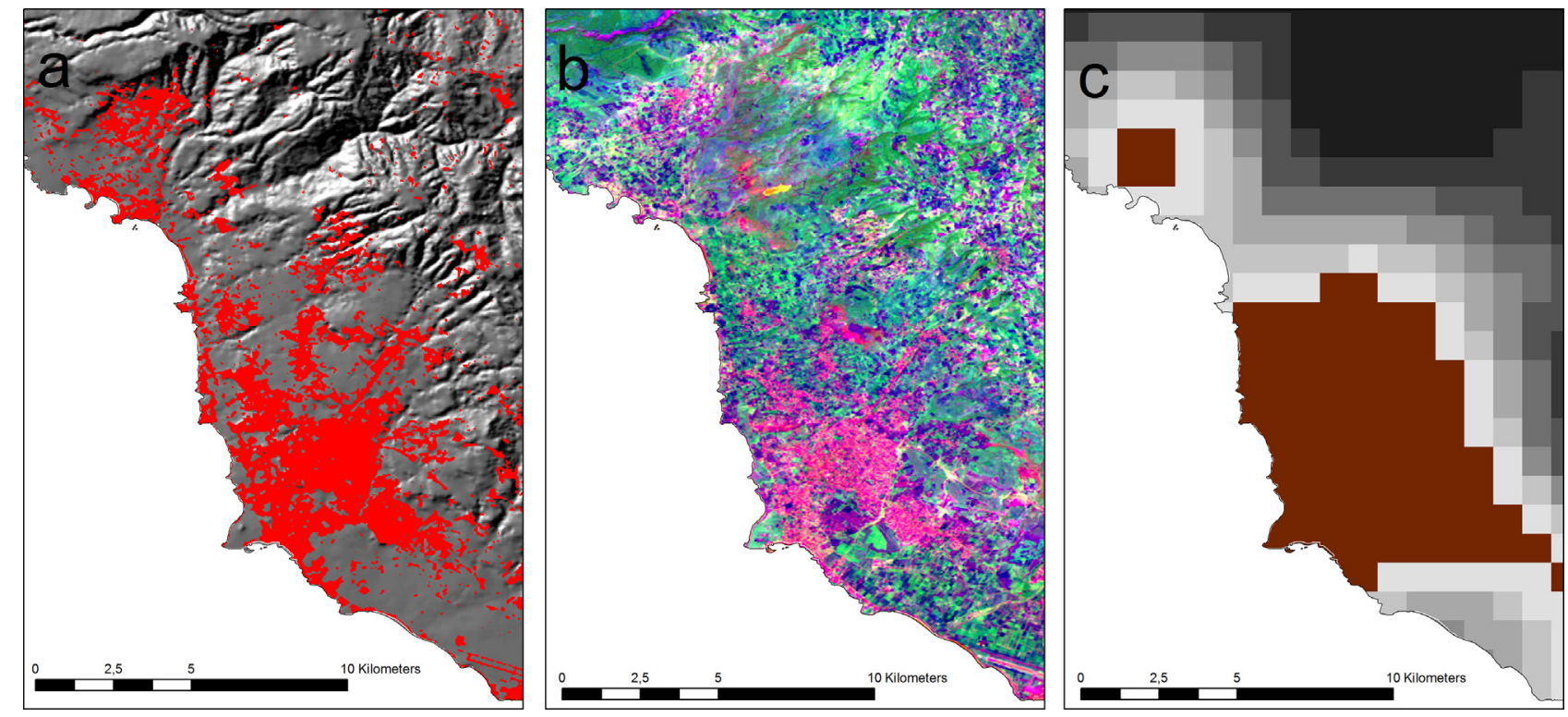

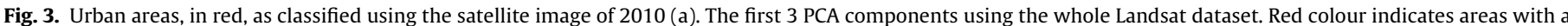

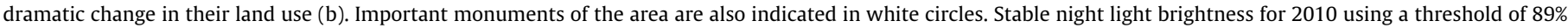
(brown colour) while gray values indicates unlighted areas (c).

\subsection{PCA and night images data}

Decomposition analysis was also applied to explore classification results. So as to compress the information of the Landsat dataset (i.e. 4 images $\times 5$ spectral bands), the PCA technique was applied to the whole dataset. PCA is a well-known orthogonal transformation where the initial information is re-projected into a new $n$-dimensional space of linearly uncorrelated variables. The first PCA component has the largest possible variance of the data, and each succeeding component (i.e. PCA2; PCA3, etc) has the highest variance possible under the constraint that it is orthogonal $[20,21]$.
The first five bands (visible-very near infrared and middle infrared part of the spectrum) of each image were combined together creating a new image with 20 different bands. Then, the PCA analysis was performed.

Fig. 3a presents the comparison between the urban areas (red colour) after the classification analysis of the Landsat image taken during 2010, while Fig. 3b, the pseudo-colour composite of the first 3 PCA components using the whole Landsat dataset. Red colour indicates areas with dramatic change, which is explained due to the highest variation of the 20 band image created during the period 1984-2010.
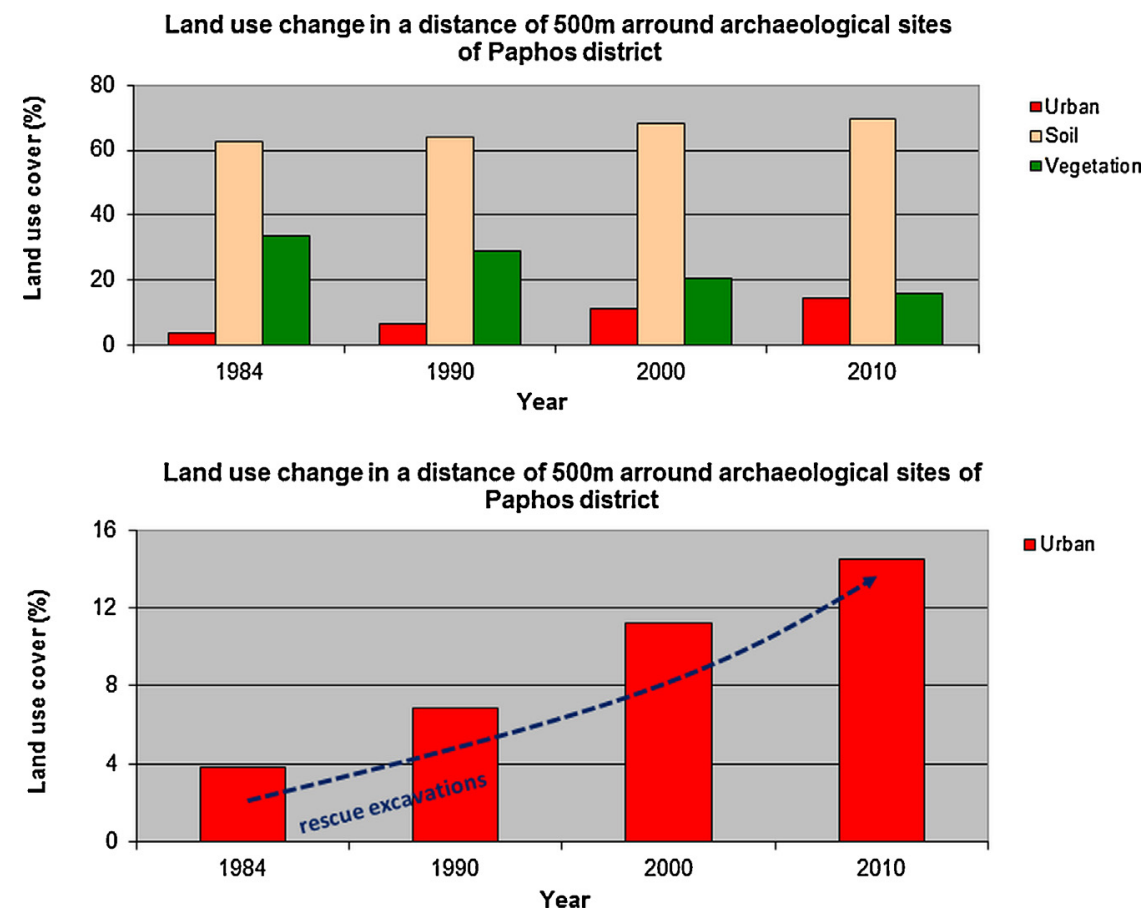

๑rban

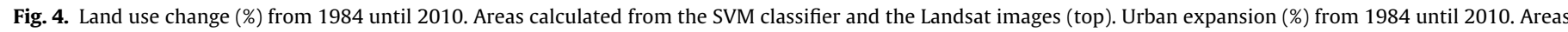

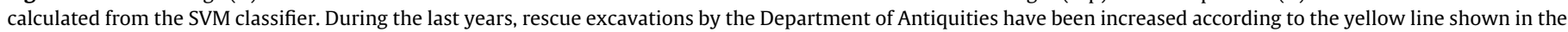
graph (bottom). 

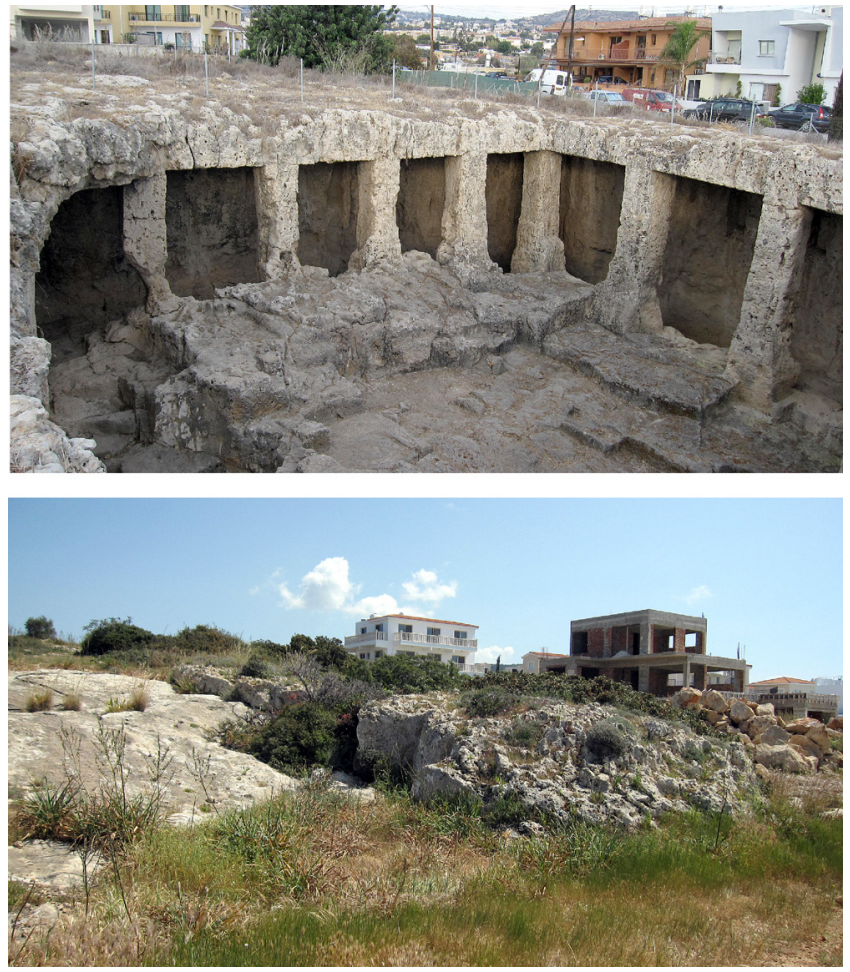

Fig. 5. In situ photographs taken from the necropolis at the site Meletis of Peyia village, showing the expansion of buildings in the vicinity of Cultural Heritage sites.

Further to the Landsat dataset, the DMSP-OLS night-time data set for 2010 was used. Night-lights are known to overestimate the spatial extent of development at the periphery of settlements and for this purpose a low light threshold of $89 \%$ is proposed [26,33]. Similar approach was followed in this study as well. Fig. $3 \mathrm{c}$ presents the results from the DMSP-OLS night-time using the $89 \%$ threshold (left). Fig. $3 c$ indicates that DMSP-OLS night-time data can be used for an optimum estimation of the urban areas cover in a low resolution analysis ( $1 \mathrm{~km}$ pixel size).

\subsection{Urban expansion in the vicinity of cultural heritage sites}

The classification results were exploited in order to evaluate the urban expansion in the vicinity of the Cultural Heritage sites of Paphos (see Fig. 1). A buffer zone of $500 \mathrm{~m}$ (i.e. 15 pixels) for each monument was set, while the area of the different land use classes was calculated. The results, as shown in Fig. 4top, indicate that urban land coverage in the vicinity of cultural heritage sites has been increased during the period 1984-2010. A more detail observation of the results (see Fig. 4, bottom) shows that urban expansion has been raised up to $350 \%$ during the last 35 years. Indeed, as it was found from the low $4 \%$ of the total land cover in 1984 , urban areas were increased to $7 \%$ in $1990,11 \%$ in 2000 and $14 \%$ in 2010 . Similar results (not shown here) have been also recorded by the authors for other cities of Cyprus as well. For the period from 1984 to 2010, approximately 15\% of vegetation and soil land cover have been turned into new built up areas. These land use changes correspond to approximately $51 \mathrm{~km}^{2}$ and $9 \mathrm{~km}^{2}$ for bare soil and vegetation coverage respectively. The pressure of these land use changes to cultural heritage of Paphos can be also observed by the number of rescue excavations performed by the Department of Antiquities (Fig. 4bottom).

\section{Discussion}

\subsection{Urban pressure for existing archaeological sites}

During the last decades, an expansion of the urban sprawl has been recorded in the broader area of Paphos District. Exten-sive construction and building development has taken place, and several areas of archaeological interest nowadays suffer from the widespread urban growth. Ancient necropolises located in the centre of modern Paphos area were among the archaeological sites that suffered the most from the building boom during the 1980s. Unfortunately, the same pattern is repeated today, though in more restrained form, in the periphery of Paphos centre. A representative example is the case of the ancient necropolis at the site Meletis of Peyia village, in the north area of Paphos, where recent construction activity has literally smothered the archaeological site (Fig. 5). The newly constructed buildings are in close proximity to the archaeological site and their height exceeds the low hill into which the rock-cut tombs are shaped. Similar case is the Hellenistic-Roman necropolis in the village Anavargos, approximately $3 \mathrm{~km}$ northeast of Nea Paphos. The construction of buildings and roads and their use by heavy traffic can be destructive for the adjacent monuments that suffer from continuous vibrations.

In contrast, the case is quite different for other archaeological sites and monuments of Paphos town that have been protected prior to the building boom of the last decades. Important sites, such as Tombs of the Kings and Nea Paphos have been declared as World Cultural Heritage sites in 1980, and therefore, these sites have remained untouched by urban sprawl. In these protected areas,
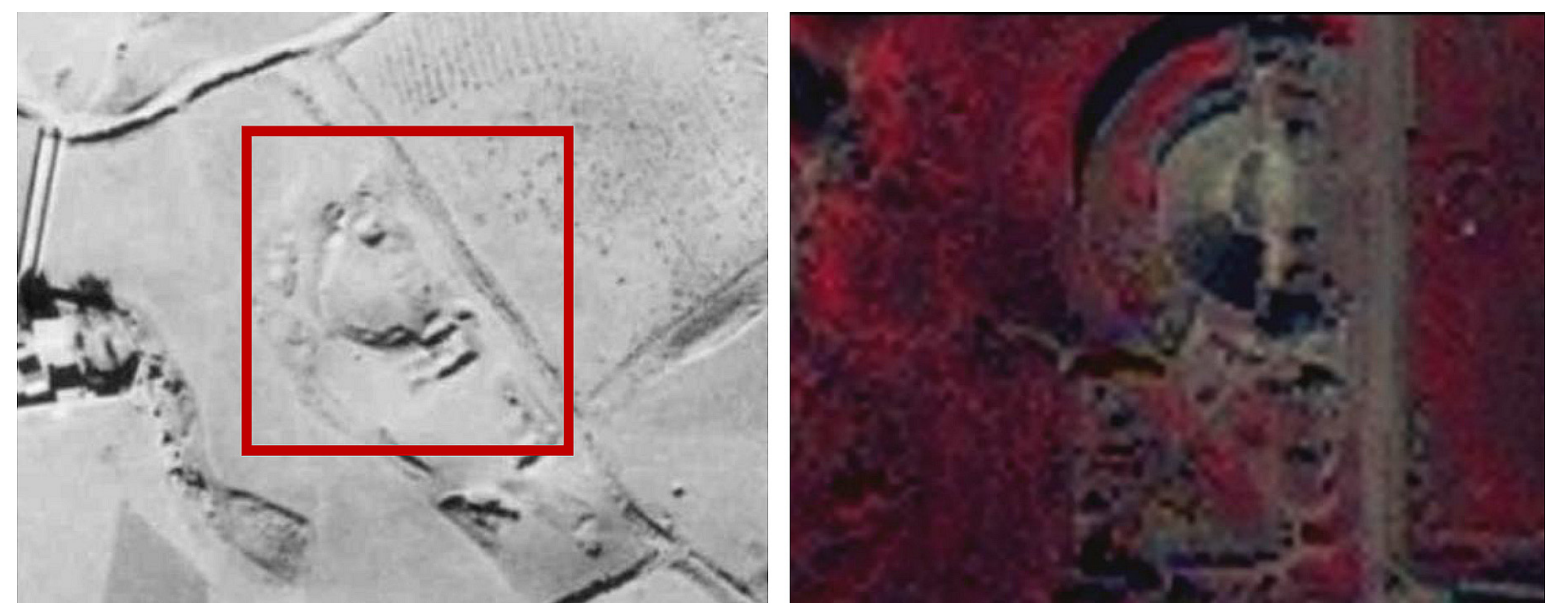

Fig. 6. Airphoto taken from 1945 from the Nea Paphos archaeological site. The Theater is clearly identified as soil mark (left), before it was excavated (right). 

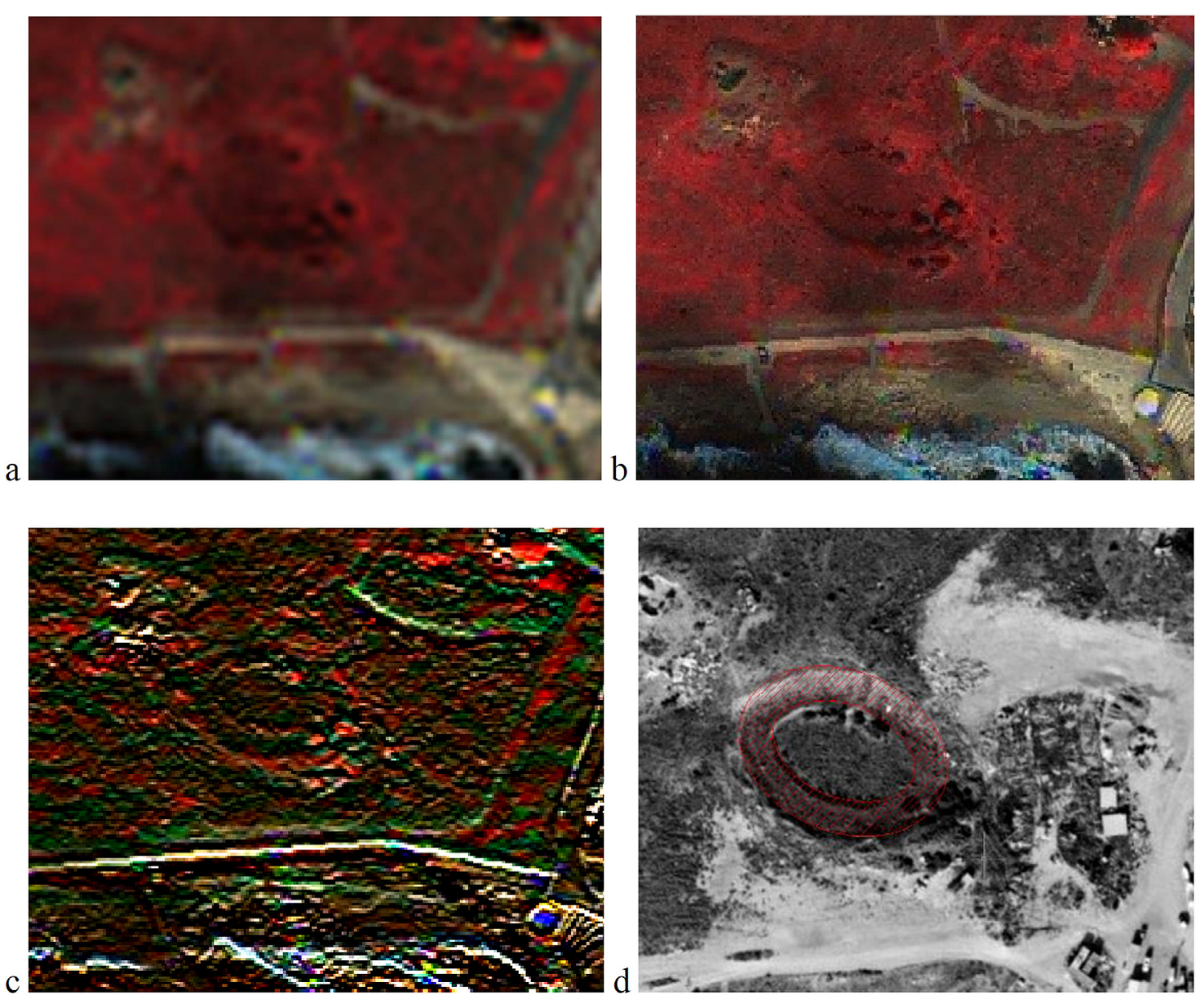

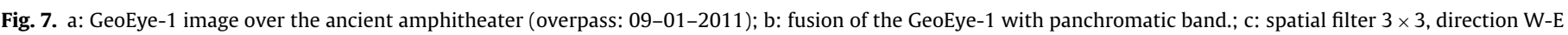
and (d) the amphitheater as shown from aerial photo of 1963.

remote sensing techniques, both from space or ground, can be systematically used to support archaeological research $[11,13,34,35]$. As it is shown in Fig. 6, archaeological relics may be identified from aerial or satellite data. The ancient theatre located in the northeast-ern part of the ancient city of Nea Paphos can be detected before the archaeologists have contacted excavations at the site. In a sim-ilar way, other buried archaeological relics within the site may be detected. Such monuments may be identified using several remote sensing techniques (e.g. soil and crop marks) and interpretation of the imagery dataset. Indeed, as it is shown in Fig. 7, the ancient amphitheater (?) - still unexcavated - located in the southern part of the archaeological site can be observed using image fusion, spatial filters, pseudo-colour etc.

\subsection{Prediction of urban expansion using satellite data}

For the aforesaid reasons, it is important to protect archaeologi-cal

sites and monuments, from future building booms and therefore contributing to a more archaeologically oriented urban planning of the still developing area of Paphos. Remote sensing techniques can be used as valid inputs for simulations and prediction models. In this study the Stochastic Markov Model was used for this purpose.

As Ahmed and Ahmed [27] argue, this kind of predictive land cover change modeling is appropriate when the past trend of land cover changing pattern is known. Urban growth modeling has evolved over recent years to capture increasingly well the details of urban morphology and structure [36]. Land use change transition probability in Markov analysis indicates the probability of making a transition from one land use class to other one within two discrete times.

The Markov chain equation was constructed using the land cover distributions at the beginning (Mt) and at the end $(\mathrm{Mt}+1)$ of a discrete time period. Under the assumption that the sample is representative of the region, these proportional changes become probabilities of land cover change over the entire sample area and form the transition matrices. The transition probability matrix is calculated and records the probability that each land cover category will change to every other category.

The Stochastic Markov Model was firstly examined and evaluated for 2010, using the Landsat data of 1990 and 2000. In the next phase, the urban expansion for 2020 was calculated. The transition probability matrix as calculated from the Landsat 1990 and 2000 images, using the IDRISI software [37], is shown in Table 4. As it was expected both vegetation and land have significant possibilities to change land cover category due to the phenological cycle of vegetation. However, water bodies, such as dams and reservoirs, have an almost zero possibility to change their land use cover type.

Table 4

Transition probability matrix for each land cover class using the Markov Chain equation.

\begin{tabular}{lllll}
\hline & Vegetation & Built up areas & Land & Water bodies \\
\hline Vegetation & 0.4124 & 0.0288 & 0.5582 & 0.0007 \\
Built up areas & 0.0891 & 0.4590 & 0.4419 & 0.0099 \\
Land & 0.0678 & 0.0320 & 0.8996 & 0.0006 \\
Water bodies & 0.0000 & 0.0003 & 0.0006 & 0.9991 \\
\hline
\end{tabular}



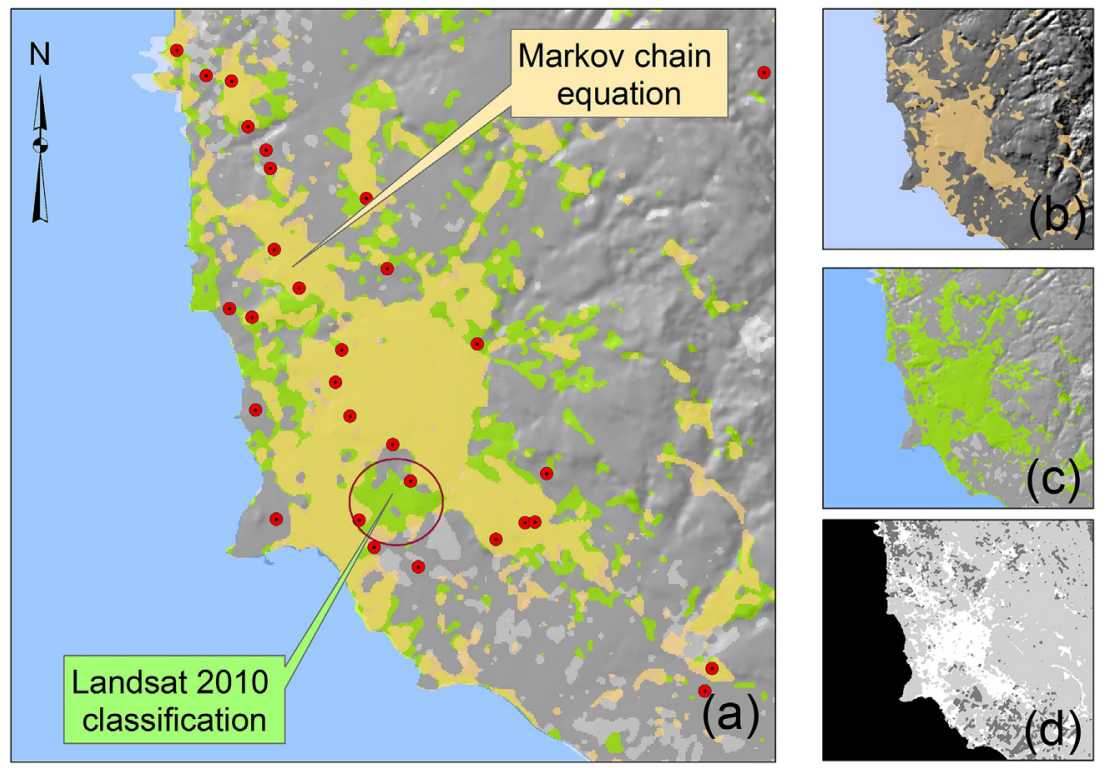

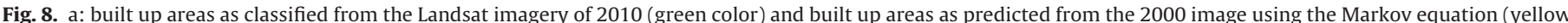

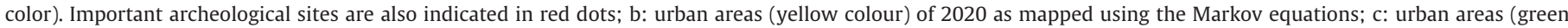

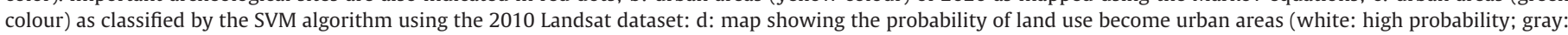
medium probability dark gray: low probability).
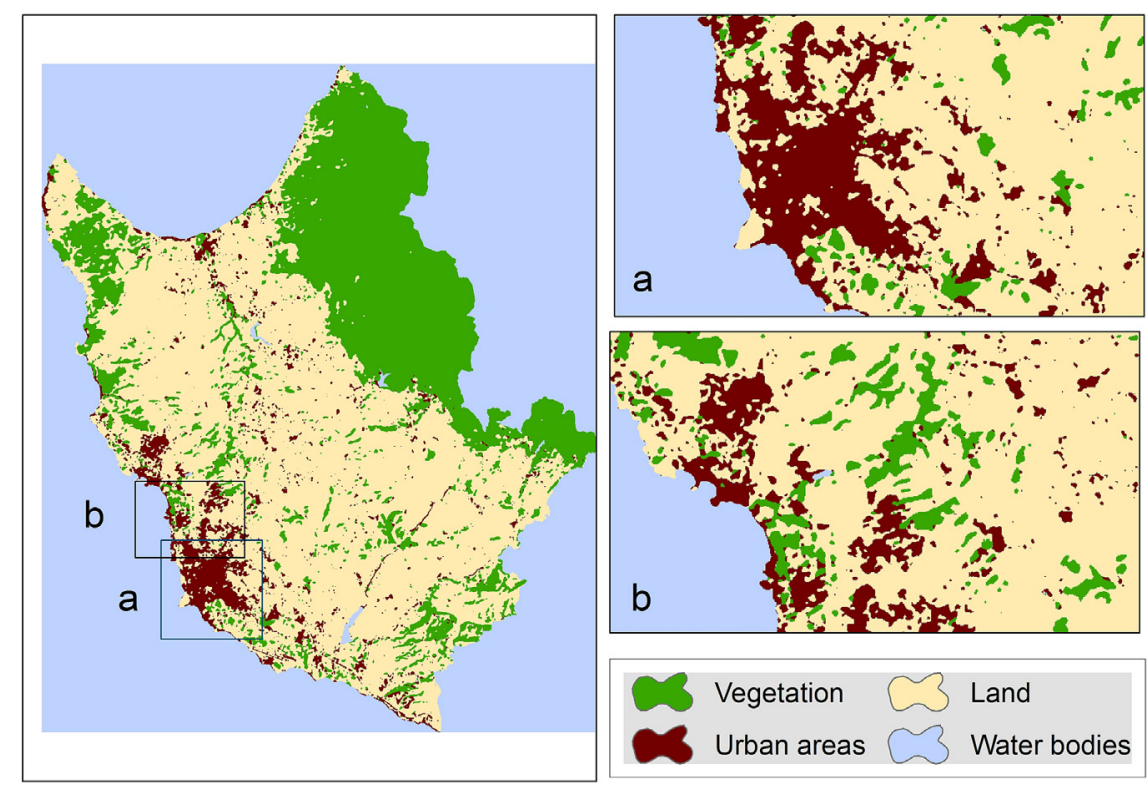

Fig. 9. Built up areas in brown as calculated from the Markov model for 2020

In addition, the transition probability matrix shows that land cover areas have more possibilities to become built up areas.

Fig. 9 illustrates the built up areas as classified from the Landsat imagery of $2010(k=95 \%)$ and built up areas as predicted using the 2000 image based on Markov equations. As it was found, the Stochastic Markov Model had a good performance for mapping potential built areas of 2010. A slightly difference of the Markov model and the reference data (2010) is seen in the southern part of the Paphos town (indicated in circle in Fig. 8). However, it should be noticed that in this region a non-normal extensive construction project took place during the last decade (University Campus).

Based on the findings of the classification analysis for 2000 and 2010, a prediction of urban areas for 2020 was made. For mapping potential urban areas for the year 2020, the land use map of 2010 was used as well the changes during the 2000-2010 decade (transition matrix). Fig. 9 shows that new urban areas are expected to be found in the perimeter of the Paphos town and the SW coast. In this region several important monuments exists, and therefore, these sites will continue to suffer from the future urban pressure.

\section{Conclusion}

This paper aims to highlight the contribution of remote sensing and GIS techniques for monitoring monuments and archaeological sites of significant historic and artistic value, threatened by urban sprawl. Paphos district, which was selected as the case study 
area, has changed dramatically during the last 35 years. Indeed, as it was found from several classification techniques applied to multi-temporal Landsat satellite dataset and the DMSP-OLS nighttime data, urban expansion has been increased by $350 \%$ during the last 35 years.

The building boom in Paphos area-town was relatively sudden and abrupt, due to large population movements in the hitherto undeveloped areas. Furthermore, this phenomenon of the urbanization has resulted extensive archaeological excavations of rescued character (Fig. 4). This is documented in the Annual Reports of the Department of Antiquities of Cyprus, where the almost absent reference to Paphos, was replaced from the mid 1980s onwards by reports on the ongoing excavations in the area (see Annual Reports of the Department of Antiquities from 1980-2008).

Further to the visible monuments (monuments and sites that have been excavated), many other important - but still unknown to us today - remain unexcavated. In this way, urban pressure can destroy potential archaeological evidence. As several researchers have already demonstrated remote sensing techniques can also be used to identify such buried archaeological features and there-fore protect these monuments $[38,39]$. Moreover, as highlighted by Valetta Convention of the Council of Europe [40], non-destructive methods are recommended for sites investigation, to be applied whenever possible. In this sense, the 11th European Archaeologiae Consilium (EAC) Symposium has recognized the significance of remote sensing methodologies in exploration, identification, doc-umentation and monitoring of the archaeological heritage in the living landscape, especially when it comes to "a shift of focus from traditional archaeological sites to landscapes and to more broadly-based inventories of monument types" [41].

Urban expansion is considered to be one of the major threats for monuments in this area. Predicted models, such as the Markov equations, have shown that in the near future (2020), even more archaeological sites will be threatened from this anthropogenic hazard. In terms of duration, archaeological excavations rank as the longest lasting field operations worldwide. Indeed, archaeological research and systematic excavations are usually long term projects, since they need to deal and synthesize with a huge amount of information and systematic work both in the field as well in the laboratories. Using such kind of predictive models, nondestructive remote sensing techniques can be used in an attempt to detect possible archaeological remains. Such results may be taken into consideration to local urban planning policies for the protection of archaeological sites.

Urban pressure may cause a series of individual problems to monuments and sites of cultural value. Some of them are related to the continuous vibration provoked either during the construction of infrastructure to cover the augmented needs of the expanded town, or by the frequent use of cars and heavy vehicles in proximity to the archaeological sites. This kind of stresses may put in question the structural efficiency of the nearby monuments. Furthermore, contaminants released by the vehicles have an indirect impact on the monuments, accelerating the deterioration mechanisms. It is noteworthy that Paphos monuments are mainly composed of a high porosity calcarenite particularly susceptible. The incompatible scale and materials of the new buildings so near to ancient con-structions arises aesthetical issues as well. Therefore, such results and systematic monitoring tools from remote sensing data can be used for protection of cultural sites. This is a strong initiative for policy makers to take immediate actions for protecting the archae-ological monuments, as well as the archaeological subsoil. The proposed methodological approach, combined to remote sensing research (satellite, aerial, geophysics, etc.), can be of great value to the Cultural Resource Management (CRM) authorities, in order to manage cultural heritage in a coherent and non-destructive way.

\section{Acknowledgements}

The results reported here are based on findings of the project "AEIФOPIA/KOIA $\Phi / 0311(\mathrm{BIE}) / 06$ ": Managing cultural heritage Sites through Space and ground Technologies using Geographical Information Systems: A Pilot application at the archaeological sites of Paphos. The project is funded by the Republic of Cyprus and the European Regional Development Funds. Thanks are given to the Remote Sensing and Geo-Enviroment Laboratory of the Department of Civil Engineering and Geomatics at the Cyprus University of Technology for its continuous support (http://www.cut.ac.cy) The authors would like to thank the Director of the Department of Antiquities Dr. Maria Hadjicosti for her permission to access the data of the Department.

\section{References}

[1] J. Chen, K. Chang, D. Karacsonyi, X. Zhang, Comparing urban land expansion and its driving factors in Shenzhen and Dongguan, China, Habitat Int. 43 (2014) 61-71.

[2] United Nations, World urbanzation prospects: The 2011 revision, UN Department of Economic and Social Affairs, New York, 2012.

[3] W. Wu, S. Zhao, C. Zhu, J. Jiang, A comparative study of urban expansion in Beijing, Tianjin and Shijiazhuang over the past three decades, Landscape Urban Planning 134 (2015) 93-106.

[4] G. Swensen, B.G. Jerpåsen, Cultural heritage in suburban landscape planning A case study in Southern Norway, Landscape Urban Planning 874 (2008) 289-300.

[5] P. Zhao, Too complex to be managed? New trends in peri-urbanisation and its planning in Beijing Cities 30 (2013) 68-76.

[6] K. Roychowdhury, H. Taubenböck, S. Jones, Delineating urban, suburban and rural areas using Landsat and DMSP-OLS night-time images Case Study of Hyderabad, India, IEEE (2011) (978-1-4244-8657-1)

[7] S.H. Al-Houdalieh, R.R. Sauders, Building destruction: the consequences of rising urbanization on cultural heritage in the Ramallah Province, Int. J. Cult. Property 16 (2009) 1-23.

[8] P.J. Lane, Future urban growth and archaeological heritage management: some implications for research activity in Africa, Conserv. Manag. Archaeol. Sites 13 (2011) 134-159.

[9] D. Hadjimitsis, A. Agapiou, D. Alexakis, A. Sarris, Exploring natural and anthropogenic risk for cultural heritage in Cyprus using remote sensing and GIS, Int J. Digit. Earth 6 (2) (2011) 115-142.

[10] G.L.A. Fry, B. Skar, G. Jerpåsen, V. Bakkestuen, L. Erikstad, Locating archaeological sites in the landscape: a hierarchical approach based on landscape indicators, Landscape Urban Planning 67 (1-4) (2004) 97-107.

[11] S. Pappu, K. Akhilesh, S. Ravindranath, U. Raj, Applications of satellite remote sensing for research and heritage management in Indian prehistory, J. Archaeol Sci. 37 (9) (2010) 2316-2331.

[12] R. Cataldo, A. de Donno, G. de Nunzio, G. Leucci, L. Nuzzo, S Siviero, Integrated methods for analysis of deterioration of cultural heritage the Crypt of "Cattedrale di Otranto", J. Cult. Herit. 61 (2005) 29-38.

[13] A. Sarris, N. Papadopoulos, A. Agapiou, M.C. Salvi, D.G. Hadjimitsis, A.W. Parkin-son, R.W. Yerkes, A. Gyucha, R.P. Duffy, Integration of geophysical surveys, ground hyperspectral measurements, aerial and satellite imagery for archae-ological prospection of prehistoric sites the case study of VésztöMágor Tell, Hungary, J. Archaeol. Sci. 403 (2013) 1454-1470.

[14] P. Canuti, N. Casagli, F. Catani, R. Fanti, Hydrogeological hazard and risk in archaeological sites some case studies in Italy, J. Cult. Herit. 12 (2000)117-125.

[15] B. Cuca, D. Oreni, R. Brumana, Digital cartographic heritage in service to the society Landscape analysis for informed decision making, in: Proceedings of the 18th International Conference on Virtual Systems and Multimedia (VSMM), 2-5 Sept, 2012, pp. 499-506.

[16] Z. Zhu, C.E. Woodcock, Continuous change detection and classification of land cover using all available Landsat data, v 144 (2014) 152-171.

[17] D.-H. Kim, J.O. Sexton, P. Noojipady, C. Huang, A. Anand, S. Channan, M. Feng J.R. Townshend, Global, Landsat-based forest-cover change from 1990 to 2000, Remote Sens. Environ. 155 (2014) 178-193.

[18] J.O. Sexton, D.L. Urban, M.J. Donohue, C. Song, Long-term land cover dynam-ics by multi-temporal classification across the Landsat-5 record, Remote Sens. Environ. 128 (2013) 246-258

[19] T. Blaschke, Object based image analysis for remote sensing, ISPRS 65 (1) (2010) $2-16$.

[20] T.M. Lillesand, R.W. Kiefer, J. Chipman, Remote sensing and image interpretation, Lehigh Press, 2004.

[21] J.B. Campbell, Introduction to Remote Sensing, The Guilford Press, New York, 2007.

[22] G. Mountrakis, J. Im, C. Ogole, Support vector machines in remote sensing: a review, ISPRS 66 (3) (2011) 247-259.

[23] B.W. Heumann, An object-based classification of mangroves using a hybrid decision tree - Support Vector Machine approach, Remote Sens. 3 (2011) 2440-2460. 
[24] A.I. Yuhendra, S.T.J. Sumantyo, H. Kuze, Assessment of pan-sharpening methods applied to image fusion of remotely sensed multi-band data, Int. J. Appl. Earth Observ. Geoinf. (2012) 18165-18175, http://dx.doi.org/10.1016/ j.jag.2012.01.013.

[25] J. Paneque-Gálvez, J.-F. Mas, G. Moré, J. Cristóbal, M. Orta-Martínez, C.A. Luz, M. Guèze, J.M. Macía, V. Reyes-García, Enhanced land use/cover classifica-tion of heterogeneous tropical landscapes using support vector machines and textural homogeneity, Int. J. Appl. Earth Observ. Geoinf. 23 (2013) 372-383

[26] C. Small, D.C. Elvidge, D. Balk, M. Montgomery, Spatial scaling of stable night lights, Remote Sens. Environ. 1152 (2011) 269-280.

[27] B. Ahmed, R. Ahmed, Modelling urban land cover growth dynamics using multitemporal satellite images a case study of Dhaka, Bangladesh, ISPRS 11 (2012) $3-31$.

[28] W. Gong, L. Yuan, W. Fan, P. Stott, Analysis and simulation of land use spatial pattern in Harbin prefecture based on trajectories and cellular automata-Markov modelling, Int. J. Appl. Earth Observ. Geoinf. 34 (2015) 207-216

[29] X. Yang, X.-Q. Zheng, R. Chen, A land use change model: integrating landscape pattern indexes and Markov-CA, Ecol. Model. 283 (10)(2014) 1-7.

[30] K. Jia, S. Liang, L. Zhang, X. Wei, Y. Yao, X. Xie, Forest cover classification using Landsat ETM+ data and time series MODIS NDVI data, Int. J. Appl. Earth Observ. Geoinf. 33 (2014) 32-38.

[31] J.J. Walker, K.M. de Beurs, R.H. Wynne, Dryland vegetation phenology across an elevation gradient in Arizona, USA, investigated with fused MODIS and Landsat data, Remote Sens. Environ. 144 (25) (2014) 85-97.
[32] X. Pan, S. Zhang, H. Zhang, X. Na, X. Li, A variable precision rough set approach to the remote sensing land use/cover classification, Comp. Geosci. 3612 (2010) 1466-1473.

[33] M.L. Imhoff, W.T. Lawrence, D.C. Stutzer, C.D. Elvidge, A technique for using composite DMSP/OLS "city lights" satellite data to map urban area, Remote Sens. Environ. 61 (1997) 361-370.

[34] A. Agapiou, D.G. Hadjimitsis, Vegetation indices and field spectro-radiometric measurements for validation of buried architectural remains Verification under area surveyed with geophysical campaigns, J. Appl. Remote Sens. 5 (2011), http://dx.doi.org/10.1117/1.3645590.

[35] R. Lasaponara, N. Masini, Detection of Archaeological Crop marks by using satellite QuickBird multispectral imagery, J. Archaeol. Sci. 34 (2007) 214-221.

[36] W.B. Rimal, Application of remote sensing and GIS, land use/land cover change in Kathmandu metropolitan city, Nepal, J. Theor. Appl. Inf. Technol. (2005) 80-86.

[37] J.R. Eastman, IDRISI Selva, Clark University, Worcester, MA, 2012

[38] R.M. Cavalli, F. Colosi, A. Palombo, S. Pignatti, M. Poscolieri, Remote hyperspectral imagery as a support to archaeological prospection, J. Cult. Herit. 8 (2007) 272-283.

[39] A. Agapiou, D.D. Alexakis, A. Sarris, D.G. Hadjimitsis, Evaluating the potentials of Sentinel-2 for archaeological perspective, Remote Sens. 6 (3) (2014) 2176-2194.

[40] Council of Europe, European Convention on the Protection of the Archaeological Heritage London, 6.V. Revised in Valetta, 16.I.1992, 1969.

[41] D.C. Cowley, EAC Occasional Paper 5, Remote Sensing for Archaeological Heritage Management, Budapest, 2011. 